\title{
The Analysis of Carbon Trade Economics and Its Policy Implication to Mitigate Climate Change in Tanzania
}

\author{
Felister Mombo*, Miriam Mrutu, Yonika Ngaga \\ Department of Forest and Environmental Economics, Chuo Kikuu, Morogoro, Tanzania \\ Email: ^fmombo@yahoo.com
}

How to cite this paper: Mombo, F., Mrutu, M. and Ngaga, Y. (2018) The Analysis of Carbon Trade Economics and Its Policy Implication to Mitigate Climate Change in Tanzania. American Journal of Climate Change, 7, 508-518.

https://doi.org/10.4236/ajcc.2018.74031

Received: December 28, 2017

Accepted: May 28, 2018

Published: September 30, 2018

Copyright $\odot 2018$ by authors and Scientific Research Publishing Inc. This work is licensed under the Creative Commons Attribution International License (CC BY 4.0).

http://creativecommons.org/licenses/by/4.0/

(c) (i) Open Access

\begin{abstract}
Tanzania is participating in the United Nations (UN) climate change mitigation strategy of reduction in Greenhouse Gases (GHGs). The strategy is implemented through both Reducing Emissions from Deforestation and forest Degradation (REDD+) and Clean Development Mechanisms (CDM) initiatives. In implementing programmes, the country developed pilot projects whereby there are preliminary findings that can be used to analyse the progress of the establishments. This study uses the findings from these pilot areas to draw policy implications on how carbon trade in the country can be enhanced to meet the UN set objectives as required by the Kyoto protocol. The findings suggest that for the sustainable carbon trade enhancement the country needs to set the institutional environment for carbon trade right. Such undertakings are not costless and that the transaction costs that would be incurred for the process need to be institutionalised to reduce the private costs in the carbon market. Moreover the policy process should be informed that at the market level there are multiple objectives that should be understood to avoid what is termed as optimization in standard economic theory, instead there should be clear definition of the specific objectives for various stakeholders involved in the carbon trade. Besides, within the carbon market framework not all stakeholders incur the same costs since natural resource transactions involve externalities. These externalities need to be identified and internalised to equally distribute the costs and benefits among the stakeholders.
\end{abstract}

\section{Keywords}

Climate Change, Carbon Trade, Property Rights, Transaction Costs

\section{Introduction}

Carbon trade originates from the Kyoto Protocol where a number of industrialised 
countries signed the protocol in December 1997 committing these countries to reduce their emissions of the main Green-House Gases (GHGs). Research confirms that these gases are responsible for the observed major changes in the climate. The climate change is ultimately affecting a number of life forms and general countries' economies in a various ways [1].

Although the efforts toward reduction of these GHGs focus on six gases [2], carbon dioxide $\left(\mathrm{CO}_{2}\right)$ is by far the largest of these by volume, representing about $80 \%$ of the total emissions of the six gases [2]. Literature reveals that almost all of the emitted $\mathrm{CO}_{2}$ comes from fossil fuels where OECD countries account for over half of the total $\mathrm{CO}_{2}$ emissions in the world while an additional four countries (Brazil, China, India and Russia) together account for a further quarter of the global total [3]. The Kyoto protocol has therefore set a standard to which such $\mathrm{CO}_{2}$ emission could be reduced (previously, by 5\% from 2008-2012), so as to reduce its impact to the climate change. In attaining such an objective a number of initiatives have been made by these OECD countries. One among such is what is being implemented under what is now termed as Reduced Emission from Deforestation and forest Degradation (REDD+) and Clean Development Mechanism (CDM) programmes.

While CDM programmes are more geared towards reduced emissions of all GHGs, REDD+ on the other side is more focused on reduction of $\mathrm{CO}_{2}$ emissions. The REDD+ implementation was accelerated when the concept was adopted and the strategies set by UN under UN-REDD. UN-REDD Programmes were created in September 2008 to assist developing countries to build capacity to reduce emissions and to participate in a future REDD+ mechanism [1]. Both REDD+ and CDM establishments are framed under the same practice of the carbon trade/market although each has its specifications as summarised in later sections. In both of these the common objective is to reduce emissions to a level that will be not detrimental to the environment as the Kyoto Protocol requires.

Tanzania is among developing countries that have signed the Kyoto protocol and is participating in both REDD and CDM initiatives with financial assistance from what are termed as Annex I parties in the UNFCCC-Kyoto protocol. Meanwhile almost all projects in Tanzania are financed by the Royal Norwegian Government. In implementing both REDD+ and CDM the country has developed pilot projects. While there are quite few studies focused on CDM, there are preliminary findings in REDD+ that can be used to analyse the progress of the establishment. This paper therefore intends to do some economic analyses that would lead to policy implications, using some preliminary empirical findings from the REDD+ pilot projects. The analyses would help to inform the policy process on how the carbon market under REDD+ can be improved to achieve the set objective as intended by the Kyoto Protocol. The theory adopted for such analyses is that of New Institutional Economics (NIE). The theorists in this school of thoughts believe that for an appropriate conclusion to be made for any economic analyses two important things must be considered: 1) Institutions do 
matter in all economic analyses. 2) The determinants of institutions are susceptible for analysis by the tools of economic theories.

\section{Theoretical and Conceptual Frame Work}

This study is framed in the theories of NIE. Different from standard economic theory, it is the belief in institutional and NIE theories that transaction costs are pervasive and may explain the fact that not all transactions are undertaken in market institutions [4]. Although there are some variations within the NIE theoretical framework [4] group them into three sub-branches: the property rights view, the transaction costs school and the specific position of Oliver, Williamson. However [4] ascertain that, all these groups are based on the idea that institutions do matter in all economic analyses and all are strongly inspired by neoclassical model whereby they do agree that such economic analyses within the specified institutions must use economic theories.

Within the framework of NIE as described by [5] four levels of social analysis are identified. These are: social theory (L1), economics of property rights (L2), transaction cost economics (L3) and neoclassical economics/agency theory (L4). In terms of these levels of social analysis, NIE is framed within L2 and L3. As a brief explanation of these two important levels, L2 constitutes the level at which the institutional environment is analysed. The famous term used to describe this level is "the rule of the game" [6]. It is at this point that informal rules become formalised into formal rules including polity, judiciary and bureaucracy. The purpose of this level is to get the institutions right and it is here that the "first order of economising" is formed. The second important level for NIE is L3. It is at this level that the governance issues are analysed. The aim is to get the governance structures right and this, forms the "second order of economising" level [5].

Although Williamson in his model recommends the use of neo-classical economic theories in the analysis of third order of economizing level, [4] who is among the advocates of the application of NIE in all economic analyses questions about the core theory of bounded rationality as understood in that school of thought. Although the details can be read in his book titled: Institutions and the environment, the brief explanation of why he does so can be summarised as follows; with vivid examples the author argues on how rationality cannot be a singular term. According to [4] rationality is plural and is not only about the individual. In his own words Vatn claims that, “... It is more generally about choosing the appropriate means to define ends. These ends may be individually defined-as instituted in the marketplace. However, they may also be established to support for example, the creations or provision of a common good. This brings the social forms of rationality on stage and consequently also different logics concerning the ways we go about attaining goals-that is, what are the appropriate means..." Further to this [7] in his evolving model of Institutions of Sustainability (IoS) (that is also framed in NIE theories and more linked to natural resource economics), introduces the concept of multifunctional nature of natural resources when undertaking such economic analyses. This study 
adopts these lines of thinking as specified by [4] [5] and [7] in analysing the carbon trade in Tanzania.

\section{Methods}

The study used both qualitative and quantitative surveys to understand the nature of transactions; associated costs and benefits of the transactions in carbon market framework. The surveys were conducted in Kilosa District in Morogoro region which was one of the pilot study areas on REDD+ project in Tanzania under the Climate Change Impact Assessment and Mitigation (CCIAM). The sample consisted of 200 households that were randomly selected to represent Kilosa District local communities who implemented the project under the supervision of Tanzania Forest Conservation Group (TFCG/MJUMITA), community based organization.

Besides, the study also used secondary data, grey and published journal articles which were sourced in internet web sites, SUA library and government offices. The study used both revealed and stated preferences to evaluate the transaction costs of carbon trade in Tanzania.

\section{The Economic Analysis of Carbon Trade}

Our analyses on carbon trade in Tanzania are based on first, second and third levels as identified in the framework of the New Institutional Economics as conceived by [6], previous presentation in the international conference on climate change [8] and the discussion and conclusion is categorised into three levels hereby referred to as first, second and third order of economising levels. The study used the empirical findings from the pilot study to discuss these economizing levels to draw some policy implications so as to inform the policy process on how carbon trade intending to mitigate climate change can be enhanced.

\section{Results Discussion and Policy Implications}

\subsection{Reduced Emission from Deforestation and Forest Degradation and Clean Development Mechanism Frameworks}

In this section we shall briefly look at the historical evolution of the two concepts of REDD and CDM and frame through which they operate. The REDD concept was initially introduced in 2005 where the focus in the beginning was on reducing emissions from deforestation. Under the initial concept, the participating countries were required to reduce deforestation below historic rates to receive compensation from an international mechanism. As negotiations and research continued on the topic, countries realized that forest degradation ${ }^{1}$ was also a significant source of emissions. To reduce forest degradation various strategies

${ }^{1}$ Forest degradation is the gradual thinning of forests-which reduces the carbon stock of a forest but does not result in the conversion of the land to another use. The causes of degradation are generally logging, fuelwood extraction, and/or fire. 
must be engaged including activities such as reduced impact logging, sustainable forest management, fuel-wood management, and firewood management. It was from this understanding that the concept of REDD was framed where it was argued that reducing emissions from deforestation and forest degradation are both resulting into what was termed REDD [9].

As negotiations on REDD continued to evolve, other activities were included such as forest conservation, sustainable management of forests, and enhancement of forest carbon stocks. While these concepts have not been fully defined yet, forest conservation generally refers to the protection of standing forests that have not historically been under threat of deforestation. Sustainable management of forests refers to activities which increase carbon stocks and/or reduce carbon emissions from forests by changing the way in which they are managed. Management changes may include implementing harvest methods that result in less damage to remaining trees, extending harvest rotations thereby leaving more carbon stored on the land, increasing the stocking of poorly stocked forests by encouraging growth of denser/healthier trees and converting previously harvested forests to no-cut protected areas. Enhancement of forest carbon stocks may include forest restoration, reforestation, and/or forestation. These activities, when added to REDD are referred to as REDD+. Finally, some countries would like to include carbon emissions from all land-use types, including agricultural land, wetlands, and others. When these activities are included, it is often referred to as AFOLU (agriculture, forestry, and other land uses) [10].

The CDM, just like REDD originates from the Kyoto Protocol [9]). It refers to one of the flexibility mechanisms that provides for emissions reduction projects which generate Certified Emission Reduction (CER) units that may be traded in emissions trading schemes [9]. As defined in Article 12 of the Kyoto Protocol, the initiative is meant to assist industrialized countries (Annex I Parties) in meeting their GHGs emission reduction commitments, at the same time supporting developing countries (non-Annex I) to attain sustainable development through the implementation of project activities, and to contribute to the ultimate objective of the UNFCCC. Main benefits that can be realized from CDM activities include sustainable industrial development, poverty reduction through improved and increased rural income, employment opportunities to the communities, availability of affordable energy sources to the rural communities, improvement of social services such as education and health, as well as enhancement of technology transfer and development [11]. Examples of CDM projects include; energy industries (renewable/non-renewable), forestry, agriculture, waste handling and disposal.

Emissions trading schemes in CDM allows Annex I countries to buy CERs and to invest in emission reductions sectors including forestry [12]. Trading in carbon credits has been reported to be a large and growing market. For example, global carbon market for transactions was estimated to be Euro 94 million worth in 2009, which is more than double the 2007 figures [11]. Between 2001, which 
were the first year CDM projects could be registered and 7 September 2012, the CDM issued about 1 billion CER units. As of 1 June 2013, 57\% of all CERs had been issued for projects based on destroying either HFC-23 (38\%) or $\mathrm{N}_{2} \mathrm{O}(19 \%)$. Among other things it is believed that growth was attributed by the start of the Phase II of EU Emission Trading Scheme (ETS) in January 2008 and to the launch of secondary CER contracts trading on the European Climate Exchange (ECX). From December 2011, trading included Carbon Capture and Storage (CCS) in the CDM carbon offsetting scheme [13].

\subsection{Institutional and Economic Analyses of REDD+ and CDM in Tanzania}

\subsubsection{First order of Economizing Level of Carbon Trade}

At the first level of analysis we shall look at the institutional arrangement (property rights) of the carbon trade in Tanzania. It is worthy to note that up to this moment Tanzania does not have its own independent policy on carbon trade beside the country adopting the REDD+ and CDM practices on voluntary basis as they are required by the Cancun Agreement [14] and [15]. The two establishments are hosted or operating under the Environmental Management Policy (1995) [16] and the Act, EMA 2005 [17].

While REDD is piloted in Tanzania on voluntary basis as required by the Cancun Agreement [14] and [18] explain that, the language used in paragraph 69 of the Cancun Agreement makes clear that once a country agrees to undertake REDD activities on its own accord, implementation has to be in accordance with the guidance and safeguards laid out in the Annex 1 of the Cancun decision. According to [18], REDD+ safeguards are broadly understood as policies, programmes, activities and measures that are designed to protect against undesirable outcomes in specific projects and programmes. They aim to address both direct and indirect impacts on communities and ecosystems, by identifying, analysing and ultimately working to manage risks and opportunities. It is so unfortunate [14] claims that, among all the 15 pilots projects of REDD+ in Tanzania, their study showed that the concept has been institutionalized only in one REDD+ pilot that is under the Jane Goodall Institute (JGI) in Kigoma Region. The mid-term review of REDD+ Tanzania also revealed that to date Tanzania lacks its own specific safeguards to implement REDD+. The ultimate goal of instituting safeguards was to ensure that the project achieve a win-win scenario between conservation and community livelihoods.

CDM establishment on the other side unlike REDD+, its practices are a little bit clear since there is a guideline which has to be followed for the parties to qualify for the carbon payments. Under the UNFCCC Kyoto Protocol, CDM projects that reduce emissions or remove carbon dioxide from the atmosphere generate CERs. The CDM project developer receives CERs after the project has successfully undergone the project cycle for CDM. The developer then sells the CERs to an operator i.e. a company or a government (Annex I entity) that requires additional CERs or EU Allowances (EUA) under the EU Emission Trading 
Scheme (ETS) trade and cap agreement. The operator can then request the conversion of the CERs into the corresponding amount of EUAs through an International Transaction Log. So far the country has only one operator/company called Green Resources certified for the carbon payment [11] [15].

However, a number of weaknesses of the CDM have been identified [18]. Several of these issues were addressed by the new Program of Activities (PoA). In 2012, the report Climate change, carbon markets and the CDM: A call to action, said governments urgently needed to address the future of the CDM (1). It suggested the CDM was in danger of collapse because of the low price of carbon in developing countries and the failure of governments to guarantee its existence into the future. Writing on the website of the Climate and development knowledge network [19], a member of the investigating panel for the report and founder of Fundacion Futuro Latinamericano, said a strong CDM is needed to support the political consensus essential for future climate progress. "Therefore we must do everything in our hands to keep it working," she said [19].

Beside, in both of these practices between REDD+ and CDM, the case studies (e.g. [14]) and [20] revealed that land tenure is one of the principal factors affecting the ways in which forest resources are managed and the manner in which benefits are shared. The claims are further extended in [21] and [14] whereby the authors argue, land tenure in Tanzania can best be described by legal pluralism. Following this, traditional systems operate in parallel with the formal system. People may have informal use rights that sometimes are viewed locally as comparable to property. Hence, there is a lot of tenure insecurity.

Forests and land are the main resources transacted in REDD+ and CDM carbon trade. It follows that if the institutional arrangement for both these transacted resources are not clearly defined in reference to carbon trade that by itself will jeopardise the carbon trade sustainability. It is a well established fact within the NIE theories that the good institutional environment determines (i.e. clearly defined property rights) the efficacy of economic transactions within any established institution including markets. This is in fact the first order of economizing level when it comes to all kinds of transactions understood within the NIE framework. Moreover the creation or rather the definition of such institutionalised transactions referred to as property rights ${ }^{2}$ are not cost less. It is this which differentiates the neoclassical economic theories from NIE [5]. From this we learn that, as a first stage of economizing in carbon trade the policy process should be informed that, if these property rights are not clearly defined and institutionalised within the government the sustainability of carbon trade establishment in Tanzania will be questionable. It is therefore most important for the country to adopt what is called positive polity in institutionalizing the carbon trade within the country.

Since the definition/creation of such property rights as explained in this section is not cost less, there are certain information required to be gathered and ${ }^{2} \mathrm{~A}$ property right is defined as an enforceable authority to undertake particular actions in a specific domain [22] 
certain negotiations to be engaged among the stakeholders involved in the trade. All such transactions involved in the gathered information and negotiations are referred to as economics of transaction cost.

\subsubsection{Second Order of Economizing Level of Carbon Trade}

Two types of costs incurred by a REDD+ trial payment project were identified for analysis in this study. The first category was transaction cost incurred by TFCG/MJUMITA project in monetary terms during implementation of a REDD+ trial payment project. They include monitoring and verification, REDD+ readiness, start up and baseline setting costs which were obtained as secondary data. The second category was transaction cost incurred by villagers in terms of time and resources spent by households during implementing REDD+ trial payments activities. Payments include transaction costs of operation, preparation and cost of individual households in attending meetings. The study revealed that transaction costs of forest management for REDD+ is relatively high (TZS 497,714 ha ${ }^{-1} \cdot \mathrm{year}^{-1}$ ) compared to TZS 211,358 and 61,362 as transaction costs of VLUP and CBFM processes and REDD+ meetings respectively (Table 1).

While this study's finding is based on the operational level transaction costs, the mid-term review [15] indicated that the REDD+ secretariat (which can be considered as a national institution responsible for all REDD+ process in Tanzania) used almost more than 50\% of the entire fund allocated for REDD+ activities in the country as management cost. This can be termed as transaction costs since they are not directly incurred within the carbon market framework. Again for the CDM case [11] it was revealed for the operator to be certified for the carbon trade certain transaction costs must be incurred including developing a project idea note which is estimated to take one week, project design process that ends with a project document which takes an estimate of six months to one year, project validation which takes about three to six months, project registration and

Table 1. Total transaction costs for implementing a REDD+ project.

\begin{tabular}{cccc}
\hline Main category & Sub-category & Total value (TZS) & $\begin{array}{c}\text { Total transaction cost } \\
\left(\mathrm{TZS} \cdot \mathrm{ha}^{-1} \cdot \mathrm{yr}^{-1}[\%]\right)\end{array}$ \\
\hline \multirow{2}{*}{ To project } & Monitoring and Verification & $166,421,389$ & $1411.0(52.20)$ \\
& Start up cost & $123,672,000$ & $1049.0(38.80)$ \\
& REDD readiness cost & $28,000,000$ & $237.0(8.70)$ \\
Baseline setting & 50,000 & $0.4(0.01)$ \\
To villagers & Sub-total & $318,143,389$ & $2697.4(99.71)$ \\
& Operation cost & 497,714 & $4.2(0.20)$ \\
& Preparation cost & 211,358 & $1.8(0.07)$ \\
REDD+ meetings & 61,362 & $6.5(0.02)$ \\
& Sub-total & 770,434 & $2704.0(100)$ \\
\hline
\end{tabular}

Source: Field surveys 2015 
at last the project credit delivery. Besides the whole process being long and cumbersome, it is very expensive for a developing country. However in the absence of transaction cost economics these costs are assumed to be zero. The basic idea here as explained by [6] is that the major role of institutions as the rule of the game is to establish a stable structure that reduces uncertainty and also capture the gains arising from specialization and division of labour. In the clear definition of the rights (the concept of property rights), it is made clear who is to do what for what compensation. The policy process should therefore not concentrate on the market institutions (the buyers and the sellers) as perceived in neo-classical economic theories but should also consider the transactions and information costs that are not clearly visible in the market structure. As a second order of economizing level it is important for the policy to establish on how such costs on transactions and information can be distributed among the stakeholders. It is on this basis we believe on the importance of transaction costs economics for the efficacy of carbon trade in Tanzania.

\subsubsection{Third Order of Economizing Level of Carbon Trade}

In this part of economic analysis we looked at the concept of buyers and sellers in reference to neo-classical economic theory. When we consider such economic analyses and link them to the carbon trade, we must therefore establish what the scope of this trade is. Literature suggests that a core idea underlying carbon trade $(\mathrm{REDD}+\& \mathrm{CDM})$ is to make performance-based payments, that is to pay forest owners and users (when we make reference to REDD+) and CDM operators, to reduce emissions and increase carbon sequestration. In this section we considered two cases such that TFCG/MJUMITA project which is this study's case and the second is that of [23] to make our inferences. The first is a result on the economic efficiency of the Kilosa pilot project where it was concluded to be positive (Table 2(b), when indirect benefits are included). Implying it is worth to undertake the project when the economy of scale is considered. That is to say if the project's transaction costs are to be internalised through government structure and if the project area can be increased to enhance the amount of carbon sequestered which is the base of the pricing, then the project is likely to break even. We used NPV values to rule out our decision and the summary of the analysis is as described in Table 2(a) and Table 2(b).

While this study used transaction cost economic theory to analyze the economics of the establishment [23], case study (the second case we adopted for this study) used a different approach [23]. Case used standard economic theories to decide on the viability of the REDD+ establishment in Mufindi District in Iringa Region. Although [23] study is not based on REDD+ pilots but the objective of the study was to determine whether the coming REDD+ initiatives will be effective. The specific objective was to assess the opportunity costs of REDD+ to the Mufindi communities as one of the candidates of the forthcoming REDD+ establishment if the concept is to be scaled up throughout the whole country. 
Table 2. (a) NPV at different discount rates (Direct benefits); (b) NPV at different discount rates (Indirect benefits included).

(a)

\begin{tabular}{cccccccc}
\hline \multirow{2}{*}{ Year } & Cost & Benefit & Net benefit & & \multicolumn{3}{c}{ NPV at $\mathbf{r}=:$} \\
\cline { 5 - 8 } & & & & $\mathbf{1 5 \%}$ & $\mathbf{2 3} \%$ & $\mathbf{3 1 \%}$ & $\mathbf{3 3 . 7 \%}$ \\
\hline 1 & $133,350,434$ & 0 & $-133,350,434$ & $-115,956,899$ & $-108,414,987$ & $-101,794,224.4$ & $-99,738,544.5$ \\
2 & $77,187,118$ & $82,747,800$ & $5,560,682$ & $4,204,674.48$ & $3,675,511.931$ & $3,240,301.847$ & $3,110,750.97$ \\
3 & $74,456,271$ & $82,747,800$ & $8,291,529$ & $5,451,814.91$ & $445,775.5444$ & $368,992.6253$ & $347,086.204$ \\
4 & $16,960,000$ & $82,747,800$ & $65,787,800$ & $37,614,388.2$ & $28,742,525$ & $22,338,817.54$ & $20,588,264.28$ \\
5 & $16,960,000$ & $82,747,800$ & $65,787,800$ & $32,708,163.6$ & $23,367,906.5$ & $17,052,532.47$ & $15,398,851.37$ \\
Total & $\mathbf{3 1 8 , 9 1 3 , 8 2 3}$ & $\mathbf{3 3 0 , 9 9 1 , 2 0 0}$ & $\mathbf{1 2 , 0 7 7 , 3 7 7}$ & $-\mathbf{3 5 , 9 7 7 , 8 5 8}$ & $-\mathbf{5 2 , 1 8 3 , 2 6 8 . 0 2}$ & $-\mathbf{5 8 , 7 9 3 , 5 7 9 . 9 5}$ & $-60,293,591.68$ \\
\hline
\end{tabular}

Source: Field surveys 2015.

(b)

\begin{tabular}{cccccccc}
\hline \multirow{2}{*}{ Year } & \multirow{2}{*}{ Cost } & \multirow{2}{*}{ Benefit } & Net benefit & \multicolumn{4}{c}{ NPV at $\mathrm{r}=:$} \\
\cline { 7 - 8 } & & & & $15 \%$ & $23 \%$ & $31 \%$ & $33.7 \%$ \\
\hline 1 & $133,350,434.00$ & $29,357,768.00$ & $-103,992,666.00$ & $-90,428,405.22$ & $-84,546,882.93$ & $-79,383,714.50$ & $-77,801,493.45$ \\
2 & $77,187,118.00$ & $112,630,568.00$ & $-10,795,650.00$ & $-8,163,062.38$ & $-7,135,732.69$ & $-6,290,804.73$ & $-6,042,535.89$ \\
3 & $74,456,271.00$ & $128,630,568.00$ & $54,174,297.00$ & $35,620,479.66$ & $29,112,396.00$ & $24,097,911.07$ & $22,685,530.98$ \\
4 & $16,960,000.00$ & $128,630,568.00$ & $111,670,560.00$ & $63,848,005.12$ & $48,788,587.88$ & $37,918,706.27$ & $34,984,814.86$ \\
5 & $16,960,000.00$ & $128,630,568.00$ & $111,670,568.00$ & $55,520,008.43$ & $39,665,521.45$ & $28,945,579.38$ & $26,173,682.66$ \\
Total & $\mathbf{3 1 8 , 9 1 3 , 8 2 3 . 0 0}$ & $\mathbf{5 2 7 , 8 8 0 , 0 4 0 . 0 0}$ & $\mathbf{1 6 2 , 7 2 7 , 1 0 9 . 0 0}$ & $\mathbf{5 6 , 3 9 7 , 0 2 5 . 6 0}$ & $\mathbf{2 5 , 8 8 3 , 8 8 9 . 7 0}$ & $\mathbf{5 , 2 8 7 , 6 7 7 . 4 8}$ & $-\mathbf{0 . 8 0}$ \\
\hline
\end{tabular}

Source: Field surveys 2015.

Both the findings of [23] and this study were not conclusive in their rulings. The decisions varied depending on what were considered in the calculations on costs and benefit analysis. While this study's results were showing how the transaction costs can be reduced when the government intervenes through subsidies [23], decision depended on the price and the nature of the proxy used to calculate the opportunity cost [23]. Results can be summarized as follows: The profitability of agriculture and woodlots in comparison with REDD+ incentives was determined by calculating the NPV for agriculture and woodlots and the total amount of cash flow of $\mathrm{CO}_{2}$ e per ha. Results show that the NPV for agriculture and woodlots were USD 2958.52 and USD 3272.94 per ha per year respectively. The cash flow per ha of $\mathrm{tCO}_{2} \mathrm{e}$ was depending on which unit price per $\mathrm{tCO}_{2} \mathrm{e}$ was adopted. Based on [24] unit price, the NPV was USD 719.87/ha and when based on [25] unit price, the NPV was USD 25,627.39 $\mathrm{ha}^{-1}$; [24] concluded their study by implying that there is no an optimal solution to what should be the viable decision when it comes to the opportunity cost as a ruling decision. This is because the economic value of alternative land uses depends on the type of the land use and the requirements for production. The above ground carbon stock of the montane forests along the Eastern Arc Mountains varies from one location to another. Also, the profitability of any land use is determined by inputs 
used for production, and the selling price of the products which indicate the opportunity costs incurred when implementing REDD+. There is no general price per $\mathrm{tCO}_{2} \mathrm{e}$, it depends on REDD+ opportunity cost when compared with alternative land uses of a particular place. Therefore careful examination of the costs involved to adopt REDD+ is very important for the initiative to be effective and sustainable.

Two important things we learn from these case studies which have also been established within Williamson's model; The inclusion of bounded rationality 1) and the acceptance of positive information and transaction cost, 2) What does this mean? It means the clearer the property rights are in their institutional arrangement the more it would be easier to identify the transaction costs and the more it would be easy for the decision on the viability of the projects. However in explaining Williamson's model [4] claims, given positive transaction costs it is impossible to undertake all the bargaining prior to contracting. This we learn from both case studies. Bounded rationality therefore implies that decision makers do not optimize unlike what is understood in standard economic theory. Instead the economic agents try to reach defined targets.

Further to this, another important message the policy process is informed from [23] case is, unlike what is assumed in standard economic theory that the commodity has two dimensions of price and quantity, the policy makers should change that perspective to consider the nature/characteristic of the resource as portrayed in this particular study. According to [5], the resources vary in their characteristics. High asset specificity which for simplicity [4] viewed as a low degree of standardisation makes it more demanding to specify the qualities of the goods or service to be delivered. As a result of low degree of standardisation which requires specification the transaction costs increases. It is therefore important to consider the characteristic of the resource in valuing natural environment. The same finding was revealed in [21] where the author concluded the valuation and management options of wetlands to be determined based on their characteristics/properties. This is well explained by [25] and [4] on their study on multifunctional nature of ecosystems and natural resources.

It is therefore important for the policy process not to focus their attention to only the price and the quantity of the resource (the carbon sequestered/stored) without considering the proxies used to calculate the opportunity costs of a particular place. A carbon sequestered in a tree grown in a catchment area for example, cannot be valued the same as that which is grown in barren land even if the two trees would have the same capacity to sequester carbon. Moreover it would be important for the information about the nature and characteristics of the environmental goods used for the transactions involved in carbon trade to be gathered and the information used to standardise the proxies for calculating opportunity costs of the sequestered/stored carbon. So far this information is lacking in the Tanzanian carbon market.

Again if we are to agree on the plurality of rationality it means, not all stakeholders can be viewed the same way when it comes to the objective setting. It 
would be important for such performance to be varied depending on the position the individuals occupy in their specified institutions. In the market institutions there would be buyers and sellers transacting biomass of the trees they own and use for example; but those are just one group of the economic agents in the carbon market institution; others may include government with its linked sectors to the market which has a role of enacting and enforcing the policies.

Although the government intervention in the carbon market reduces a lot of the transaction costs arising from carbon trade, it is worthy to note the objective of the government may differ from that of the private entities involved in the trade. If that is understood then whose performance should be compensated and how? This is an important question to be analysed by the policy process for the sustainability of carbon trade in Tanzania. So far with what is experienced in the pilot projects these objectives are not differentiated, it looks as if all the stakeholders carry the same objective of climate change mitigation. Climate change mitigation might be a global objective but along the process, individuals and other stakeholders involved in the carbon market, depending on their bounded rationality might respond differently. It is therefore important for the policy process to identify such differentiated objectives and set the performance based on what is expected from these differentiated stakeholders.

It is again important to understand that the transactions involved in natural environmental goods and services exhibits externalities of both natures (positive and negative). In the carbon market there would be those who would be incurring more costs and other benefits that are not laboured for. As an example, if a community in an up-stream shall preserve a forest that is located in a catchment area people of the down-stream shall benefit from water that would increase from such forest management option. All the same if the up-stream community may plant trees that would consume more water than it would release to the downstream, people in the downstream might be negatively impacted through the reduced water flows. If such information would be made available and these costs internalized some of the transaction costs might be reduced through internal mechanisms other than inflating the carbon price which is supposed to be paid by the Annex I parties. So far this is not considered in the current setting of the carbon market.

\section{Conclusions and Recommendation}

We conclude by saying that for a proper economic analysis of the carbon trade in Tanzania the policy process should consider all levels of economic analysis to make sure the costs and benefits are equally distributed among the stakeholders. Moreover if the core objective of the carbon trade is to reduce emission through Annex I parties to assist the non-annex I countries to offset their emissions then the payments should not only be based on the biomass of the carbon sequestered without considering the whole institutional arrangement and its associated transaction costs. It should be understood that for these trade to be sustainable the institutional environment should be pre-determined which include the crea- 
tion and definition of property rights which is more costly compared to buying and selling the specified carbon in an established market. However within the government not all sectors incur the same cost, since natural resource transactions involve externalities. These externalities need to be identified and those who enjoy the positive externalities (within the country) need to be compensating the losers through certain agreements including environmental taxes. The same is to the individual stakeholders depending on various targets defined from operation to national levels. For all this information to be availed to the policy makers, a research is needed. It is therefore very important for the whole carbon market establishment to consider the transaction and information costs anticipated for setting the right institutional environment in Tanzania before they think on the carbon to be bought and sold in the established market. Consequently, if there would not be a careful evaluation of the opportunity costs of climate change mitigation, the cost of participation in the trade to some of the stakeholders especially those whose livelihoods depend on natural environment, shall be higher than the benefits of their participation in mitigating the changes.

\section{Conflicts of Interest}

The authors declare no conflicts of interest regarding the publication of this paper.

\section{References}

[1] UN-REDD (United Nations Collaborative Programme on Reducing Emissions from Deforestation and Forest Degradation in Developing Countries) Programme Strategy 2011-2015. International Environment House, Geneva.

[2] Ahmad, N. and Wyckoff, A. (2003) Carbon Dioxide Emissions Embodied in International Trade of Goods. OECD Science, Technology and Industry Working Papers, 2003/15, OECD.

[3] OECD (2012) OECD Environmental Outlook to 2050. OECD, Netherland.

[4] Vatn, A. (2005) Institutions and the Environment. Edward Elgar, Cheltenham.

[5] Williamson, O.E. (2000) The New Institutional Economics: Taking Stock, Looking Ahead. Journal of Economic Literature, 38, 595-613.

https://doi.org/10.1257/jel.38.3.595

[6] North, D.C. (1990) Institution, Institutional Change and Economic Performance. Cambridge University Press, New York. https://doi.org/10.1017/CBO9780511808678

[7] Hagedorn, K. (2007) Towards an Institutional Theory of Multifunctionality. In: Mander, Ü., Helming, K. and Wiggering, H., Eds., Multifunctional Land Use. Meeting Future Demands for Landscape Goods and Services, Springer, Heidelberg, Berlin, 105-124. https://doi.org/10.1007/978-3-540-36763-5_7

[8] Mombo, F. and Ngaga, Y. (2013) The Analysis of Carbon Trade Economics and Its Policy Implication to Mitigate Climate Change in Tanzania: New Institutional Economics Perspective. International Conference on Climate Change 2013: Climate Change, Sustainable Intensification and Food Security in Sub-Saharan Africa, Morogoro, Tanzania, 13-15 November 2013.

[9] IPCC (2007) Glossary J-P. In (book section): Annex I. In: Metz, B., et al., Eds., Cli- 
mate Change 2007: Report of the Intergovernmental Panel on Climate Change, Cambridge University Press, Cambridge, U.K., and New York, USA.

[10] Kajembe, G.C., Silayo, D.A., Kitula, M.M., Lyatura, N., Mutabaz, K.J., Massawe, F. and Vatn, A. (2012) REDD+ Realities: Lessons Learned from REDD+ Pilot Projects in Kondoa and Rungwe Districts, Tanzania. Proceedings of the First Climate Change 22 Impacts, Adaptation and Mitigation Programme Scientific Conference, Held at Blue Pearl Hotel, Dar es Salaam, Tanzania, 2-3 January 2012.

[11] Green Resource (2010) Development of Clean Development Mechanism Project in Tanzania; Leason Learnt. Standvein, Norway.

[12] Grubb, M. (2003) The Economics of the Kyoto Protocol. World Economics, 4, 143-189.

[13] World Bank (2010) World Development Report 2010: Development and Climate Change. The International Bank for Reconstruction and Development/The World Bank, Washington DC.

[14] Kajembe, G.C., et al. (2017) The REDD+ Process in Tanzania: The Village as an Arena for Defining and Defending Local and National Interests.

[15] Ministry of Natural Resources and Tourism (MNRT)/UN-REDD Programme (2012) Capacity Needs Assessment of Government Institutions at Central, Regional, District and Local Levels for the Establishment and Management of a REDD+ Scheme in Tanzania. Final Report, 104 p.

[16] United Republic of Tanzania (URT, 1995) Environmental Policy 1995. Vice President Office, Dar es Salaam.

[17] URT (2005) Environmental Management Act, 2005. Vice President Office, Dar es Salaam.

[18] Kant, P., Chaliha, S. and Wu, S. (2011) REDD Safeguards of Cancun. IGREC Working Paper IGREC 19, Institute of Green Economy, New Delhi.

[19] Yolanda, K. (2012) Safeguarding the Clean Development Mechanism Will Benefit Southern and Northern Nations Alike.

[20] Mombo, F., Lusambo, L.P., Speelman, S., Buysse, J., Munishi, P. and Van Huylenbroeck, G. (2014) Scope for Introducing Payments for Ecosystems Services as a Strategy to Reduce Deforestation in the Kilombero Wetlands Catchment Area. Forest Policy and Economics, 38, 81-89. https://doi.org/10.1016/j.forpol.2013.04.004

[21] Zahabu, E., Eid, T., Kajembe, G.C., Mbwambo, L., Mongo, C., Sangeda, A., Malimbwi, R.E., Katani, J.Z., Kashaigili, J. and Luoga, E. (2009) Forestland Tenure Systems in Tanzania: An Overview of Policy Changes in Relation to Forest Management. INA Fragrapport 14, Department of Ecology and Natural Resource Management, Norwegian University of Life Sciences, Ás, $24 \mathrm{p}$.

[22] Edella, S. and Elinor, O. (1992) Property-Rights Regimes and Natural Resources: A Conceptual Analysis. Land Economics, 68, 249-262. http://www.jstor.org/stable/3146375

[23] Faraji, N. (2013) Opportunity Costs of REDD+ to the Communities of Mufindi District, Iringa, Tanzania. MSc. Thesis, Sokoine University of Agriculture, Morogoro.

[24] Nordhaus, W.D. (1993) Optimal Greenhouse-Gas Reductions and Tax Policy in the Dice Model. The American Economic Review, 83, 313-317.

[25] Jacob, A., Craig, J. and Fisher, G. (2005) Transportation Cost Analysis: A Case Study of the Total Cost of Private and Public Transport in Auckland. Environmental Science and Policy, 9, 55-66. https://doi.org/10.1016/j.envsci.2005.09.001 